Ann. Biol. anim. Bioch. Biophys., I962, 2 (3), 265-266.

\title{
DÉVELOPPEMENT D'CEUFS TRIPLOIDES EXPÉRIMENTAUX CHEZ LA LAPINE
}

\author{
Ondine BOMSEL-HELMREICH et $\mathrm{C}$. THIBAULT \\ avec la collaboration technique de Micheline GERARD \\ Station de Recherches de Physiologie animale, \\ Centre national de Recherches zootechniques, Jouy-en-Josas (Seine-et-Oise)
}

Dans une note précédente (BoMSEL-HEImREICH et Thibault, I962), nous avons attiré 1'attention sur la possibilité d'obtenir très régulièrement des œufs triploïdes par rétention $\mathrm{du} 2^{\mathrm{e}}$ globule polaire en faisant agir, in vitro, la colcémide dans des délais très précis par rapport à la pénétration du spermatozoïde.

La présente note rapporte les possibilités de développement de tels œufs, lorsqu'ils sont regreffés dans des Lapines-hôtes.

L'étude a porté sur $46 \mathrm{I}$ œufs transplantés après 7 heures de culture in vitro (après fécondation) dans 38 Lapines-hôtes.

TABLEAU

\begin{tabular}{|c|c|c|c|c|c|c|c|c|}
\hline \multirow{2}{*}{$\begin{array}{l}\text { Age des embryons } \\
\text { (jours) }\end{array}$} & \multirow{2}{*}{\begin{tabular}{|} 
Nombre de \\
blasto- \\
cystes ou \\
d'embryons
\end{tabular}} & \multicolumn{3}{|c|}{ Triploïdes } & \multicolumn{2}{|c|}{ Mosaïques $2 n / 3 n$} & \multirow{2}{*}{ Diploïdes } & \multirow{2}{*}{$\begin{array}{l}\text { Embryons } \\
\text { dégénérés( }{ }^{(1)}\end{array}$} \\
\hline & & normaux & $\begin{array}{l}\text { dégéné- } \\
\text { rescents }\end{array}$ & $\begin{array}{l}\text { p. } 100 \\
\text { total }\end{array}$ & normaux & $\begin{array}{l}\text { dégéné- } \\
\text { rescents }\end{array}$ & & \\
\hline $\begin{array}{l}\text { Avant implantation } \\
5-61 / 2\end{array}$ & 414 & 31 & - & 73 & 3 & - & 8 & 2 \\
\hline $8-1^{\prime} t$ & 43 & 14 & 17 & 79 & 一 & 3 & 5 & $4+4 *$ \\
\hline 15 & $1 / k$ & 2 & 6 & 66 & - & 4 & - & $2+2^{*}$ \\
\hline $17-20$ & 14 & - & - & - & 一 & - & - & $14+19 *$ \\
\hline $\begin{array}{l}\text { (1) Sans mitos } \\
\text { * Sites d'im! }\end{array}$ & plantations & as embr & & & & & & \\
\hline
\end{tabular}

Les examens des blastocystes ou des embryons ont été effectués du $5^{\mathrm{e}}$ au $2 \mathrm{O}^{\mathrm{e}}$ jour Les numérations chromosomiques ont été effectuées à partir d'écrasements dans l'acétone-orcéine selon une technique déjà décrite (PIko, BOMSEI-HELMREICH, I960).

L'ensemble des expériences et des résultats sont rapportés dans le tableau. On constate que :

Io) La proportion des hétéroploïdes est élevées : 80 hétéroploïdes sur 93 embryons récupérés, soit $86 \mathrm{p}$. Ioo environ. 
$\left.2^{\circ}\right)$ Les anomalies signant la dégénérescence, à savoir retard de croissance de l'embryon ou pycnose nucléaire, vont en proportion croissante jusqu'au $\mathrm{I} 5^{\mathrm{e}}$ jour.

$\left.3^{\circ}\right)$ A partir du $I 7^{\mathrm{e}}$ jour on ne retrouve plus d'embryon vivant.

On doit remarquer également qu'avant l'implantation les œufs récupérés ne représentent que 35 p. Ioo des œufs transplantés 4 ou 5 jours auparavant; mais les chances de fécondation in vitro, plus faibles que dans la fécondation in vivo (70 p. 10o au maximum), expliquent en partie cette faible valeur.

Les causes de cette mort à mi-gestation sont d'autant moins évidentes que les embryons triploïdes vivants ne présentent pas d'anomalies apparentes.

Il est possible qu'il existe une incompatibilité antigénique entre la mère diploïde et le fotus triploïde.

D'autres hypothèses peuvent être formulées que nous développerons ultérieurement.

Reçu pour publication en octobre 1962.

SUMMARY

DEVELOPMENT OF EXPERIMENTALLY INDUCED TRIPLOID EGGS IN TIIE RABBIT

The authors previously described a method for the regular in vitro production of triploid eggs, in which colcemid is introduced into the culture medium just before the penetration of the spermatozoïd.

This paper reports the results of experiments on the development of these triploid eggs when transferred to fostermothers.

46r cultivated eggs treated in the above manner were transferred into 38 Rabbits. 93 embryos were recovered between the $5^{\text {th }}$ and I $_{5}$ th day of gestation, 80 ( $86 \mathrm{p}$. 100) were heteroplid, mainly triploid $(70)$.

The number of retarded embryos and of pycnotic cells progressively increase until the $5^{\text {th }}$ day. After the 17 th day no living embryo was found.

Triploidy seems to involve death of the embryo at about mid-gestation.

\section{RÉFÉRENCES BIBLIOGRAPHIQUES}

Bomsel-Helmreich O., 'limbault C., I962. Fécondation in vitro en présence de colchicine et polyploïdie expérimentale chez le Lapin. Ann. Biol, anim., Bioch. Biophys., 2, 9・1 2.

Piko L., Bomsel-Helmreich O., ig6o. Triploid rat embryos and other chromosomal deviants after colchicine treatment and polyspermy. Nature, 186, 737-739. 